\title{
An interactive portal to empower cancer survivors: a qualitative study on user expectations
}

\author{
Wilma Kuijpers • Wim G. Groen • Romy Loos • \\ Hester S. A. Oldenburg • Michel W. J. M. Wouters • \\ Neil K. Aaronson • Wim H. van Harten
}

Received: 24 September 2014 / Accepted: 5 January 2015/Published online: 27 January 2015

(C) The Author(s) 2015. This article is published with open access at Springerlink.com

\begin{abstract}
Purpose Portals are increasingly used to improve patient empowerment, but are still uncommon in oncology. In this study, we explored cancer survivors' and health professionals' expectations of possible features of an interactive portal.

Methods We conducted three focus groups with breast cancer survivors ( $n=21)$, two with lung cancer survivors $(n=14)$, and four with health professionals $(n=31)$. Drafts of possible features of an interactive portal were presented as static screenshots: survivorship care plan (SCP), access to electronic medical record (EMR), appointments, e-consultation, online patient community, patient reported outcomes (PROs) plus feedback, telemonitoring service, online rehabilitation program, and online psychosocial self-management program. This presentation was followed by an open discussion. Focus groups were audiotaped, transcribed verbatim, and data were analyzed using content analysis.

Results Important themes included fulfillment of information needs, communication, motivation, quality of feedback, and supervision. Cancer survivors were primarily interested in features that could fulfill their information needs: SCP, access to their EMR, and an overview of appointments. Health
\end{abstract}

\footnotetext{
W. Kuijpers · W. G. Groen · R. Loos · N. K. Aaronson •

W. H. van Harten $(\square)$

Division of Psychosocial Research and Epidemiology,

The Netherlands Cancer Institute, Plesmanlaan 121, 1066

CX Amsterdam, The Netherlands

e-mail: w.v.harten@nki.nl
}

H. S. A. Oldenburg • M. W. J. M. Wouters

Division of Surgical Oncology, The Netherlands Cancer Institute,

Amsterdam, The Netherlands

W. H. van Harten

Department of Health Technology and Services Research, University of Twente, Enschede, The Netherlands professionals considered PROs and telemonitoring as most useful features, as these provide relevant information about survivors' health status. We recommend to minimally include these features in an interactive portal for cancer survivors. Conclusions This is the first study that evaluated the expectations of cancer survivors and health professionals concerning an interactive portal. Both groups were positive about the introduction of such a portal, although their preferences for the various features differed. These findings reflect their unique perspective and emphasize the importance of involving multiple stakeholders in the actual design process.

Keywords Oncology $\cdot$ Cancer survivors $\cdot$ Health professionals $\cdot$ Focus group $\cdot$ Interactive portal

\section{Introduction}

Improvements in cancer screening and treatment in combination with an ageing population lead to a rapid increase of the number of people that is diagnosed with cancer or that has been successfully treated for cancer (cancer survivors) [1]. Approximately $60 \%$ of them survive at least 5 years after diagnosis, and they often experience a range of symptoms and functional limitations that affect their daily lives and their well-being $[1,2]$. The majority of cancer survivors have strong information needs related to diagnosis, treatments, side-effects, and lifestyle factors [3, 4].

To cope with these challenges, it seems imperative to provide cancer survivors with the knowledge, skills, and motivation to positively influence their health status, which is commonly referred to as patient empowerment [5]. The Internet has shown to be effective in this regard [6], because it can easily provide personal information and health interventions. 
In the health-care setting, this is often done through secured portals, online applications with a personal login, often directly connected to the hospital's electronic medical record.

To date, very little is known about the appropriate specifications of such a portal in the oncology setting. To obtain this information, we conducted a systematic literature review regarding portals for patients with a chronic disease. We identified seven features that were commonly used and evaluated their relevance for cancer survivorship care following the recommendations of the Institute of Medicine [2]. These seven features included education, self-monitoring, feedback/ tailored information, self-management training, a personal exercise program, and communication with either health professionals or patients [7].

However, with our review, we found only limited information on user experiences and preferences, and the available information was not specific to oncology practice. It is thus unknown what cancer survivors and their health professionals expect from an interactive portal. The involvement of end users in the developmental process of a technology increases the likelihood that the technology actually will be used [8]. Therefore, the aim of this study was to explore the expectations of an interactive portal among cancer survivors and health professionals by means of focus groups.

\section{Materials and methods}

\section{Participants}

We conducted separate focus groups with breast and lung cancer survivors and health professionals to obtain their unique viewpoints. All participants were recruited from the Antoni van Leeuwenhoek hospital, which is part of the Netherlands Cancer Institute, a comprehensive cancer center in Amsterdam, The Netherlands.

Breast and lung cancer survivors were chosen because of the relatively high incidence of these tumors [9] and their distinct physical components (e.g., disease characteristics, impairments) and rehabilitation options. We purposively sampled survivors to ensure a range in sociodemographic and clinical characteristics such as age and treatment stage [10]. Eligibility criteria included (1) being adult, (2) undergoing curative treatment or within 5 years of treatment completion (without metastases), (3) being able to understand and speak Dutch, and (4) having at least minimal experience with computers and Internet (i.e., having a computer at home with Internet connection and being able to use it). For practical reasons, potentially eligible survivors were either approached by a nurse practitioner (breast) or with an informational letter (lung), both followed by a phone call. Those willing to participate were scheduled for a focus group session and received a confirmation letter.
All health professionals involved in the care for breast or lung cancer survivors were approached by an e-mail in which we explained the purpose of the study. Those who were interested were scheduled for a focus group session. The institutional review board designated this study as health-care quality improvement, exempting it from formal review and informed consent procedures.

\section{Focus group procedures}

The focus groups took place in our institute and were facilitated by two of the researchers (WK and WG). Participants verbally consented to audiotaping of the session and completed a short questionnaire about their sociodemographics (including Internet use and experience). Subsequently, the topic of the focus group was introduced, and, to facilitate an open discussion, it was emphasized that participants were free to express their opinions and that both positive and negative responses were respected.

In order to help cancer survivors to become familiar with the opportunities of an interactive portal, we demonstrated drafts of nine possible features of such a portal using screenshots with pictures showing examples of graphs, content, and exercises (see Table 1). These screenshots were developed by the researchers in collaboration with the IT

Table 1 Possible features of an interactive portal

\begin{tabular}{|c|c|}
\hline Feature & Description \\
\hline Survivorship care plan (SCP) & $\begin{array}{l}\text { Tailored information about diagnosis, } \\
\text { treatment, follow-up, and health } \\
\text { promotion }\end{array}$ \\
\hline $\begin{array}{l}\text { Access to the electronic } \\
\text { medical record (EMR) }\end{array}$ & $\begin{array}{l}\text { Insight into personal medical } \\
\text { information (e.g., on diagnostic tests, } \\
\text { treatments, and correspondence) }\end{array}$ \\
\hline Appointments & $\begin{array}{l}\text { Overview of past and future } \\
\text { appointments, the possibility to make } \\
\text { and/or change appointments }\end{array}$ \\
\hline E-consultation & $\begin{array}{l}\text { Secured e-mail communication with } \\
\text { health professionals }\end{array}$ \\
\hline Online patient community & $\begin{array}{l}\text { Discussion forum that facilitates } \\
\text { communication with fellow survivors }\end{array}$ \\
\hline $\begin{array}{l}\text { Patient-reported outcomes } \\
\text { (PROs) and related } \\
\text { feedback }\end{array}$ & $\begin{array}{l}\text { Self-reported data on health status, } \\
\text { followed by an overview of results } \\
\text { and additional information }\end{array}$ \\
\hline $\begin{array}{l}\text { Telemonitoring of physical } \\
\text { parameters }\end{array}$ & $\begin{array}{l}\text { Body worn sensors that measure and } \\
\text { upload data on, e.g., blood pressure } \\
\text { or heart rate that can be accessed by } \\
\text { survivors and health professionals }\end{array}$ \\
\hline Online rehabilitation program & $\begin{array}{l}\text { Information, homework assignments and } \\
\text { self-reports to improve physical func- } \\
\text { tioning and physical activity }\end{array}$ \\
\hline $\begin{array}{l}\text { Online psychosocial self- } \\
\text { management program }\end{array}$ & $\begin{array}{l}\text { Psycho education, homework and self- } \\
\text { reports to decrease distress (e.g., } \\
\text { symptoms of anxiety or depression) }\end{array}$ \\
\hline
\end{tabular}


department of our institute. Those features were based on the ones we identified in our literature review [7], and they were presented one-by-one. Subsequently, we had an open discussion to obtain all possible viewpoints regarding each particular feature.

For health professionals, the focus groups also included a demonstration, covering similar features as were presented to patients. In addition to an open discussion about possible pros and cons of the proposed features for both survivors and health professionals, we also posed specific questions on the possible impact of the interactive portal on their job performance (e.g., "How could the interactive portal, as presented, make you more efficient at work?").

\section{Analyses}

We generated verbatim transcriptions of the audiotaped sessions and two researchers (WK and RL) read all the transcriptions to familiarize themselves with the data. We used an inductive content analysis that results in themes emerging from the data [11]. WK and RL independently selected all meaningful text fragments of two randomly selected manuscripts. All text fragments were discussed, and after resolving discrepancies, RL selected the text fragments of the remaining transcripts and discussed them with WK. Subsequently, WK and $\mathrm{RL}$ assigned codes to the text fragments, reflecting the words of the participants in a more abstract way. Finally, the number of codes was reduced by combining similar codes into more comprehensive themes [11] by RL. For example, codes like "exchange of information" and "sharing experiences" were combined into the theme "communication." All themes were discussed with WK, and in case of persisting disagreement, the judgment of a third researcher (WG) was decisive.

Finally, the expectations (themes) per feature resulted in a recommendation to include (clear majority of positive expectations) or exclude (clear majority of negative expectations) each feature in an interactive portal for cancer survivors and under what conditions. In case of competing expectations (i.e., no clear majority pro or con), we looked for easy/practical solutions to overcome the negative expectations so that those features could be included as well.

\section{Results}

Participants

We conducted three focus groups with breast cancer $(n=21)$ and two with a total of 14 lung cancer survivors. Their mean age was 52.9 years (range 27-76) and 61.6 years (range 5279), respectively. Further characteristics are shown in Table 2.
In the four focus groups with health professionals $(n=31)$, individuals from medical ( $n=7$; e.g., radiotherapists, nurse practitioners), paramedical ( $n=10$; physical therapists, dieticians, etc.), and psychosocial professions $(n=14$; e.g., social workers, psychiatrist) were represented. Their mean age was 45.5 years (range 24-62) and 81\% were female. They had been working in the institute for 13 years on average (range $<1-30$ ). Computer and Internet skills were self-rated as being quite good (mean=5.1 on a seven-point scale).

\section{Focus group results}

Results are presented per feature. Expectations of breast and lung cancer survivors were generally comparable, unless explicitly stated differently. The themes that emerged are highlighted in italics. In addition to these themes, several requirements and concerns that were identified are reported. Finally, we present recommendations for an interactive portal for cancer survivorship.

\section{Survivorship care plan}

Two themes related to the survivorship care plan (SCP) emerged: fulfillment of information needs and the opportunity to re-read information. The majority of cancer survivors expressed a need for information about side effects that could occur on the long-term, about what to expect in the future and

Table 2 Characteristics of cancer survivors

\begin{tabular}{|c|c|c|}
\hline Characteristic & $\begin{array}{l}\text { Breast cancer } \\
(n=21) \\
n(\%)\end{array}$ & $\begin{array}{l}\text { Lung cancer } \\
(n=14) \\
n(\%)\end{array}$ \\
\hline \multicolumn{3}{|l|}{ Gender } \\
\hline Male & $0(0)$ & $7(50)$ \\
\hline Female & $21(100)$ & $7(50)$ \\
\hline \multicolumn{3}{|l|}{ Treatment stage } \\
\hline$<1$ year after treatment & $9(43)$ & $14(100)$ \\
\hline$>1-5$ years after treatment & $12(57)$ & $0(0)$ \\
\hline \multicolumn{3}{|l|}{ Education } \\
\hline Low (primary school) & $0(0)$ & $2(14)$ \\
\hline $\begin{array}{l}\text { Middle (high school/vocational } \\
\text { education) }\end{array}$ & $14(67)$ & $5(36)$ \\
\hline High (college/university) & $7(33)$ & $7(50)$ \\
\hline \multicolumn{3}{|l|}{ Marital status } \\
\hline Single & $6(29)$ & $2(14)$ \\
\hline \multirow[t]{2}{*}{ Married/cohabiting } & $15(71)$ & $12(86)$ \\
\hline & Mean (range) & Mean (range) \\
\hline Computer skills $^{\mathrm{a}}$ & $5.4(1-7)$ & $4.6(2-7)^{\mathrm{b}}$ \\
\hline Internet skills $^{\mathrm{a}}$ & $5.4(1-7)$ & $4.5(2-7)^{\mathrm{b}}$ \\
\hline
\end{tabular}


advice for a healthy lifestyle. They also appreciated the overview of diagnosis and treatment information; it seems useful to re-read this information.

"I would like to know what I can expect. And why I am feeling certain things and if they could be caused by the treatment. You cannot call the hospital for everything. So it is handy to have this information there [on the portal]."

Several health professionals indicated that the SCP could be useful to provide information that cancer survivors need, for example about the period after treatment completion:

"I think it can really help people if there is a kind of path, well, especially if they have completed treatment, we often hear from people 'what to do now?' and that they need some grip.” (nurse practitioner)

\section{Access to the EMR}

The opportunity to re-read information also applied to having access to their personal EMR. Most cancer survivors especially appreciated the possibility to access the results of medical examinations online:

"And sometimes, when you have been to your doctor, you are thinking 'what exactly did he say?'. Then it would be convenient to have a look."

Another theme that emerged was communication; some survivors indicated that the accessibility of information from the EMR could help to improve communication with either their family or their health professionals:

"Now, I sometimes don't know how to say things [to my family], as a results of which I cannot explain diseaserelated issues properly. This [access to the EMR at home] would be perfect, a good aid."

The last theme was anxiety. Both cancer survivors and health professionals anticipated that access to the EMR could evoke many questions due to a lack of understanding. Survivors indicated that an explanation of medical jargon was required and all participants agreed that the medical information should only be accessible after a consultation with a health professional. Some were worried about security and privacy issues.

"Yes, an explanation would be convenient. Yes, because who would understand all these numbers? I mean, not everyone is familiar with hemoglobin levels and what they mean."

\section{Appointments}

Two themes emerged concerning appointments: fulfillment of information needs and ease of use. Cancer survivors expressed the need for an overview of past and future appointments for example for this practical reason:

"It would be practical to see the history of all my appointments. I have been needing this information for my insurance company several times as well."

Some suggested to receive a short report of each appointment, although the majority recommended that this would fit better in the EMR and some indicated that they were not in need of such a report. Ease of use was expected from the possibility to make and change appointments online. Health professionals indicated that this feature was not relevant to them.

\section{E-consultation}

Communication and quality of feedback were the emerging themes. Many cancer survivors expected that communication would improve, because when sending an e-mail, you have time to formulate your questions and you can ask questions that you forgot about during a consultation:

"During appointments with my doctor, I always feel stressed. E-consultation would provide me with a way of asking questions that I did not think of during the visit."

However, some of them thought that a phone call would be more efficient. Similarly, health professionals anticipated that it would be time-consuming to answer e-mails. Both survivors and health professionals worried about the quality of feedback of the answers that could be provided or obtained via e-mail, as this would be sensitive to misinterpretation.

"If you do not see people, their facial expression or [hear] the tone of asking something, then it can be very difficult to provide a correct answer." (physical therapist)

Requirements included a limited response time (survivors) and a central e-mail box per profession in order to structure the responses (health professionals).

\section{Online patient community}

Again, communication and quality of feedback were important themes. Survivors assumed that an online patient community could be used to share experiences with others, although they were interested in exchanging practical information (e.g., about how to obtain wigs), rather than in sharing emotions. 
Survivors and health professionals doubted the quality of feedback that could be provided via a forum. As a result, all participants indicated that it would be important to have a moderator who could check, and, if necessary, adjust messages.

"All types of messages are placed in such a community. I think that you, that you [as a hospital] cannot take the responsibility for the ideas that patients exchange." (social worker)

Also, they pointed out that several cancer associations already have such a community, which would make a hospitalbased one redundant.

\section{PROs and related feedback}

Relevant themes were knowledge about health status, communication, and motivation of health professionals. The information that could be retrieved from patient reported outcomes (PROs) would increase survivors' and professionals' knowledge about the health status of survivors. It was expected that communication would improve through feedback from the PROs, because consultations could be better prepared:

"By doing this [completing a PRO], you can better inform your doctor about how you are exactly doing, and it prevents skipping important health aspects during a consultation." (cancer survivor)

On the other hand, various survivors doubted the motivation of health professionals to have a look at their PROs, due to the extra time that may be needed. This was supported by health professionals; they doubted about who would be responsible for checking and discussing PROs.

\section{Telemonitoring of physical parameters}

Survivors indicated that using telemonitoring would increase the knowledge about their health status. Health professionals agreed on this and expected that telemonitoring could be especially useful for specific rehabilitation goals:

"I can really imagine, for return to work for example it is about ergonomics and physical capacity and so on. And what would be more efficient than monitoring someone at work, seeing how someone arranges his schedule, and being able to give feedback, like: 'you've been working on the computer for 3 hours now, you'd better do some exercises.'” (physical therapist)

However, breast cancer survivors indicated that you should be well motivated to use telemonitoring, which was illustrated by their argument that they would only use it if it is medically imperative:

"I would really limit this to what you were saying, lung function, that is really important to monitor. But I would not make it too technical, and I do not want to see online that I should go for a walk or something."

\section{Online rehabilitation program}

The opportunity to fulfill information needs about rehabilitation by obtaining (survivors) or providing (professionals) accessible information was appreciated. This information could include movies of exercises and personal advice. Survivors and health professionals both believed that online rehabilitation requires a strong motivation of survivors to read the information and to exercise at home. Survivors thought that supervision is important to ensure that exercises are performed correctly:

"If you only have those pictures [as instruction for exercise], I think...sometimes it is not clear what you have to do exactly, and if you really do the wrong exercise then the pain only increases."

\section{Online psychosocial self-management program}

All participants thought that face-to-face supervision would be necessary to solve mental problems. Like a lung cancer survivor stated:

"But well, in case of anxiety or depression, which are mental problems, you know. Sometimes you express a problem but the actual problem is different and only a professional can determine what exactly is wrong with you."

However, participants also acknowledged that such a program could be used for less severe problems, possibly as supplement to usual care. Furthermore, health professionals could provide relevant information to fulfill an information need of survivors (e.g., assignments to learn to cope with emotions).

Table 3 shows a summary of the expectations (themes) per feature, a recommendation whether to include each feature in an interactive portal for cancer survivors or not and under what conditions.

\section{Discussion}

In this qualitative study, we investigated breast and lung cancer survivors' and health professionals' expectations of an 
Table 3 Overview of expectations (themes) and resulting recommendations

\begin{tabular}{|c|c|c|c|}
\hline Feature & Cancer survivors $^{\mathrm{a}}$ & Health professionals ${ }^{\mathrm{a}}$ & Recommendation \\
\hline Survivorship care plan & $\begin{array}{l}\text { Fulfillment of information needs }(+) \\
\text { Opportunity to re-read information }(+)\end{array}$ & Provision of relevant information $(+)$ & Include \\
\hline Access to EMR & $\begin{array}{l}\text { Opportunity to re-read information }(+) \\
\text { Communication }(+) \\
\text { Anxiety }(-)\end{array}$ & Anxiety (-) & $\begin{array}{l}\text { Include, as long as anxiety is minimized } \\
\text { (for example by including a medical } \\
\text { dictionary and by first discussing results } \\
\text { in a consultation) }\end{array}$ \\
\hline Appointments & $\begin{array}{l}\text { Fulfillment of information needs }(+) \\
\text { Ease of use }(+)\end{array}$ & Not applicable & Include \\
\hline E-consultation & $\begin{array}{l}\text { Communication }(+/-) \\
\text { Quality of feedback }(-)\end{array}$ & $\begin{array}{l}\text { Communication }(-) \\
\text { Quality of feedback }(-)\end{array}$ & Exclude \\
\hline Online patient community & $\begin{array}{l}\text { Communication }(+/-) \\
\text { Quality of feedback }(-)\end{array}$ & Quality of feedback (-) & $\begin{array}{l}\text { Exclude, and add a link to existing } \\
\text { communities instead }\end{array}$ \\
\hline PROs + feedback & $\begin{array}{l}\text { Knowledge of health status }(+) \\
\text { Communication }(+) \\
\text { Motivation of health professional }(-)\end{array}$ & $\begin{array}{l}\text { Knowledge of health status }(+) \\
\text { Communication }(+) \\
\text { Motivation of health professional }(-)\end{array}$ & $\begin{array}{l}\text { Include, as long as health professionals are } \\
\text { being stimulated to discuss the results }\end{array}$ \\
\hline Telemonitoring & $\begin{array}{l}\text { Knowledge of health status }(+) \\
\text { Motivation of survivor }(+/-)\end{array}$ & Knowledge of health status $(+)$ & Include, especially for lung cancer survivors \\
\hline $\begin{array}{l}\text { Online rehabilitation } \\
\text { program }\end{array}$ & $\begin{array}{l}\text { Fulfillment of information needs }(+) \\
\text { Motivation of survivors }(-) \\
\text { Supervision }(-)\end{array}$ & $\begin{array}{l}\text { Provision of relevant information }(+) \\
\text { Supervision }(-)\end{array}$ & $\begin{array}{l}\text { Exclude, unless a combination with face-to- } \\
\text { face meetings is possible }\end{array}$ \\
\hline $\begin{array}{l}\text { Online psychosocial } \\
\text { self-management } \\
\text { program }\end{array}$ & $\begin{array}{l}\text { Fulfillment of information needs }(+/-) \\
\text { Supervision }(-)\end{array}$ & $\begin{array}{l}\text { Provision of relevant information }(+/-) \\
\text { Supervision }(-)\end{array}$ & $\begin{array}{l}\text { Exclude, unless a combination with face-to- } \\
\text { face meetings is possible }\end{array}$ \\
\hline
\end{tabular}

${ }^{\mathrm{a}}(+)$ positive expectation (-) negative expectation (+/-) mixed expectation

interactive portal to empower cancer survivors. The focus groups have resulted in useful feedback regarding different possible features. Important themes that emerged were the fulfillment of information needs, the opportunity to re-read information, anxiety, quality of feedback, communication, motivation, and supervision. Based on participants' feedback, we recommend that an interactive portal for cancer survivors at least includes a SCP, access to the EMR, appointments, PROs and related feedback, and telemonitoring (all under certain conditions).

Survivors were most positive about features that could provide them with personally relevant information, including a SCP, access to their EMR, and appointments. Health professionals considered PROs and telemonitoring as most useful from their perspective, possibly enabling them to improve medical decision-making. Their preferences for different features may reflect differences in the perceived value of an interactive portal. Survivors anticipate using an interactive portal to improve (knowledge about) their health status. In contrast, health professionals anticipate using the portal to improve the provision of care by having access to PRO and telemonitoring information about their patients' symptoms and (self-reported) functional status. Survivors' expectations regarding telemonitoring of physical parameters differed, which could be related to differences in sociodemographic characteristics, disease characteristics, and different treatments with associated (side) effects [12]. Lung cancer survivors may perceive the possible benefits of monitoring vital data after lung resection, in contrast to breast cancer survivors, who (in general) receive less extensive surgery and have an overall better health status.

The concern that survivors expressed about the limited quality of feedback that they would receive via econsultations is comparable to a study on patients' experiences with web-based communication with their health professionals. Patients prefer e-consultation for specific purposes (e.g., prescription renewals, basic medical content) and faceto-face communication for others (e.g., information about treatment, questions about side-effects) [13]. We did not anticipate survivors' negative view of a hospital-based online patient community, as the literature on online cancer support groups suggests that individuals who participate in such groups tend to cope more effectively with their disease [14], have less depressive feelings, and improved social contacts [15]. Possibly our participants are not aware of the potential benefits of using these communities, and they also referred to already existing patient communities that could be used.

Most cancer survivors and health professionals indicated that they would require face-to-face supervision for rehabilitation and psychosocial support. Studies in the fields of chronic pain and rheumatology also found that participants anticipate on the value of face-to-face supervision of a health professional $[16,17]$. Furthermore, it is known that several contacts with a therapist result in less dropout and better adherence to treatment 
programs [18], which implies that combining an Internet program with face-to-face support would be a good compromise. This will increase the motivation of cancer survivors, which will contribute to empowerment. Other empowerment-related aspects like knowledge and skills are sufficiently covered by the remaining recommended features.

This study has methodological limitations that should be addressed. First, the focus groups were conducted in a single center and participating cancer survivors were limited to those with breast and lung cancer after active treatment, which may restrict the generalizability of our results. However, we used a purposive sampling procedure to include participants with a variety in sociodemographic and clinical variables, and the number of participants was reasonable for qualitative research. Furthermore, survivors indicated that the features that they endorsed could also be useful during treatment. Second, we were not able to include medical oncologists in the focus groups due to their busy schedules. Although we do not have any reason to be believe that their perspective would be substantially different from that of those health professionals who did participate in the focus groups, this is something that cannot be ruled out entirely. Finally, except for one lung cancer survivor, all participants had at least minimal experience with computers and Internet. Obviously, these individuals are most likely to actually start using an interactive portal. However, it is important to further investigate the expectations of inexperienced individuals, to be able to develop a portal that can be widely used.

Despite these potential limitations, our study is, to our knowledge, the first to systematically investigate the views of cancer survivors and their health professionals regarding an interactive portal. The information that we have generated regarding their expectations can inform the design and implementation of an interactive portal in oncology practice. A next step would be to explore the technical and practical possibilities in order to develop and test prototypes. Subsequently, the feasibility of using an interactive portal in clinical practice should be established. Once this is achieved, the (cost-) effectiveness of using an interactive portal on both patient-related and professional-related aspects can be evaluated. At the patient level, outcome measures should include patient empowerment, compliance with treatment and follow-up advise, satisfaction with care, and health-related quality of life. At the professional level, relevant outcome measures would be workload and job efficiency, awareness of patients' symptoms and functional limitations, and satisfaction with the care process.

\section{Conclusion}

Cancer survivors' and health professionals' expectations of an interactive portal were obtained by a qualitative approach. Expectations differed slightly between breast and lung cancer survivors and to a larger extent between survivors and health professionals. More work is needed regarding prototyping and feasibility testing to develop a user-friendly portal that has the potential to effectively empower cancer survivors.

Acknowledgments This research is financially supported by Alpe d'HuZes, a foundation which is part of the Dutch Cancer Society (KWF Kankerbestrijding). Grant number NKI 2010 - 4854. This study is part of the A-CaRe Program, www.a-care.org. The authors acknowledge the ACaRe2Move Research Group.

Conflict of interest The authors declare that they have no competing interests.

Open Access This article is distributed under the terms of the Creative Commons Attribution Noncommercial License which permits any noncommercial use, distribution, and reproduction in any medium, provided the original author(s) and the source are credited.

\section{References}

1. Rowland JH, Bellizzi KM (2014) Cancer survivorship issues: life after treatment and implications for an aging population. J Clin Oncol 32(24):2662-2668

2. Hewitt M, Greenfield S, Stovall E (2006) From cancer patient to cancer survivor: lost in transition. National Academies Press, Washington, DC

3. Beckjord EB, Arora NK, McLaughlin W, Oakley-Girvan I, Hamilton AS, Hesse BW (2008) Health-related information needs in a large and diverse sample of adult cancer survivors: implications for cancer care. J Cancer Survivorship 2(3):179-189

4. Kent EE, Arora NK, Rowland JH, Bellizzi KM, Forsythe LP, Hamilton AS, Oakley-Girvan I, Beckjord EB, Aziz NM (2012) Health information needs and health-related quality of life in a diverse population of long-term cancer survivors. Patient Educ Couns 89(2):345-352

5. Aujoulat I, d'Hoore W, Deccache A (2007) Patient empowerment in theory and practice: polysemy or cacophony? Patient Educ Couns 66(1):13-20

6. Samoocha D, Bruinvels DJ, Elbers NA, Anema JR, van der Beek AJ (2010) Effectiveness of web-based interventions on patient empowerment: a systematic review and meta-analysis. J Med Internet Res 12(2)

7. Kuijpers W, Groen WG, Aaronson NK, van Harten WH (2013) A systematic review of web-based interventions for patient empowerment and physical activity in chronic diseases: relevance for cancer survivors. J Med Internet Res 15(2)

8. Berg M (1999) Patient care information systems and health care work: a sociotechnical approach. Int J Med Inform 55(2):87-101

9. Nederlandse Kankerregistratie (2014) Incidentie en sterfte van kanker. http://www.cijfersoverkanker.nl/kerncijfers-over-kanker-49. html. Accessed 10 Sept 2014

10. Marshall MN (1996) Sampling for qualitative research. Fam Pract 13(6):522-526

11. Patton MQ (1990) Qualitative evaluation and research methods. Sage publications, Inc., London

12. Archer N, Fevrier-Thomas U, Lokker C, McKibbon KA, Straus S (2011) Personal health records: a scoping review. J Am Med Inform Assoc 18(4):515-522

13. Hassol A, Walker JM, Kidder D, Rokita K, Young D, Pierdon S, Deitz D, Kuck S, Ortiz E (2004) Patient experiences and attitudes about access to a patient electronic health care record and linked web messaging. J Am Med Inform Assoc 11(6):505-513 
14. Klemm P, Bunnell D, Cullen M, Soneji R, Gibbons P, Holecek A (2003) Online cancer support groups: a review of the research literature. Comput Inform Nurs 21(3):136-142

15. Hong Y, Peña-Purcell NC, Ory MG (2012) Outcomes of online support and resources for cancer survivors: a systematic literature review. Patient Educ Couns 86(3):288-296

16. Cranen K, Drossaert CH, Brinkman ES, Braakman-Jansen AL, IJzerman MJ, Vollenbroek-Hutten MM (2012) An exploration of chronic pain patients' perceptions of home telerehabilitation services. Health Expect 15(4):339-350
17. Ferwerda $M$, van Beugen S, van Burik A, van Middendorp $H$, de Jong EM, van de Kerkhof PC, van Riel PL, Evers AW (2013) What patients think about E-health: patients' perspective on internet-based cognitive behavioral treatment for patients with rheumatoid arthritis and psoriasis. Clin Rheumatol 32(6):869-873

18. Dedding C, van Doorn R, Winkler L, Reis R (2011) How will e-health affect patient participation in the clinic? A review of e-health studies and the current evidence for changes in the relationship between medical professionals and patients. Soc Sci Med 72(1):49-53 